\title{
The Effect of Discourse Markers Instruction on EFL Learners' Writing
}

\author{
Nader Assadi Aidinlou \\ Department of English Language and Linguistics, Islamic Azad University \\ Ahar Brach, Ahar-Tabriz 2km. Ahar, East Azarbaijan, Iran \\ Tel: 98-914-116-7312＿E-mail: Naderasadi@yahoo.com \\ Hakimeh Shahrokhi mehr (Corresponding author) \\ Department of English Language and Linguistics, Islamic Azad University \\ Ahar Branch,Ahar-Tabriz 2km.Ahar, East Azarbaijan, Iran \\ Tel: 98-914-758-0198_Ｅ-mail:aydamehr@ymail.com
}

\author{
Received: February 22, 2012 \\ Accepted: March 7, 2012 \\ Published: April 15, 2012 \\ doi:10.5430/wje.v2n2p10 \\ URL: http://dx.doi.org/10.5430/wje.v2n2p10
}

\begin{abstract}
Writing is one of the four skills in language learning and it should be paid more attention. In this regard, creating contexts which is value coherence in pragmatic level, and cohesion in semantic level is important. Knowledge about the discourse Markers (DMs), amongst other things, be used to improve writing skill. DMs are expression such as "now, well, so, which signal a sequential relationship between the current basic message and previous discourse. The present paper focuses on the instruction of the DMs and its effect on learners ' writing ability. To do this, two groups as control and experimental were chosen from Shoukoh Iran English Institute in Tabriz, Iran. Both groups were asked to fill the gaps with the best option from among the DMs suggested. Then treatment sessions were conducted for experimental group while during that period, control group held back to receive such a treatment. Analyzing the misuse and inappropriateness of DMs occurring to their writing, pre-test, and investigating the relevant and suitable application of DMs appearing in their writing, post-test, and concludes with the suggestion that teaching text markers to learners should be paid more attention. And also the result reveals the effectiveness of teaching text markers to students in enhancing their awareness and sensitivity of discourse and consequently raising their writing levels.
\end{abstract}

Keywords: Discourse markers, Cohesion, Coherence, Texture

\section{Introduction}

In sperber and Wilson's relevance theory, the DMs can be seen as a signpost which constrains the interpretation process and the concomitant background selection (Jucker, 2002). Discourse markers as the binding elements of a text in creating a meaningful discourse have been viewed from different dimensions in language studies. Brown and Yule (1983) defined discourse as "the analysis of language in use". They believed that such an outlook could not restrict the description of linguistic forms independent of the purposes or functions they serve in human affairs. Hatch (1992:1) defined discourse analysis as the study of language communication, spoken and written. To understand discourse and its scope, It is necessary to identify different elements which contribute to the creation of discourse. One of the elements referred to in different literatures is text markers or discourse markers. According to Halliday and Hassan (1976) cohesion in English deals with those elements which create cohesion in a text and shape contexts in extended pieces of written or spoken language. They refer to cohesive devices in a very broad sense and divided them into reference, substitution, ellipsis, and conjunctive. Schiffrin (1992) refer to different type of DMs which are to some extent similar to Halliday and Hassan conjunctives. In both Schiffrin (1992) and Halliday and Hassan (1976) the different types of conjunctives referred to, and divided into four general and major parts as "additive, adversative, causal, temporal. These connective elements represent the generalized types of connection which are recognized as holding between sentences. As Halliday and Hassan (1976) believed these connections are not logical but textual.

When we are planning to write a well-organized text, cohesion and coherence must be taken into consideration. The organization of sentence of a text or a written discourse is not like putting up bricks one upon one, there are some relationship between those sentences. Halliday and Hassan have defined a text as "not just a string of sentences. It is not 
simply a long grammatical unit, something of the same kind as a sentence, but differing from it in size-—-a sort of super sentence, a semantic unit"(1976:291). Halliday and Hassan identify five main cohesive devices in English discourse: reference, substitution, ellipsis, lexical cohesion and conjunction.

Conjunction, or connective element, which is what Halliday called DMs, involved the use of formal markers (i.e. discourse markers) to relate sentences, clauses and paragraphs to each other. The difference of the conjunction with reference, substitution, or ellipsis is that it does not instruct the reader to find missing information by looking for it in the text. Instead, conjunction signals the way the writer wants the reader to relate what is about to be said to what has been said before.

According to Feng (2010), some DMs are summarized as follows:

Additive: and, or also, in addition, furthermore, besides, similarly, likewise, by contrast, for instance;

1. Adversative: but, yet, however, instead, on the other hand, nevertheless at any rate, as a matter of fact;

2. Causal: so, consequently, it follows, for, because, under the circumstances, for this reason;

3. Continuatives: now, of course, well, anyway, surely, after all; etc.

The conjunctive elements (DMs) presuppose the presence of other components in the discourse" (Halliday, 1976). DMs not only give cohesion to a text, they also cohere two sentences together.

In fact it is not easy to list definitively all the items that perform the conjunctive role in English. Single-word conjunctions merge into phrasal and clausal ones, and there is often little difference between the linking of two clauses by a single-word conjunction, a phrasal one, or a lexical item somewhere else in the clause, a fact Winter (1977) has pointed out. Finally, DMs are distinguished from other types of commentary markers, from vocatives, interjections, and from expressions such as oh, y'know, I mean, and because, often treated as a part of this group (Fraser, 2002).

Within the past fifteen years or so there has been an increasing interest in the theoretical status of DMs, focusing on what they are, what they mean, and what functions they manifest in texts. Fraser (1999) proposed that DMs are conjunctions, adverbs, and prepositional phrases that connect two sentences, but the current sentence or utterance with its immediate context. DMs have been investigated in classroom oral discourse (Hays,1992), informal settings (Lee, 1999; Muller, 2004; Trillo, 2002), reading (Abdullah Zadeh, 2006; Jalilifar \& Alipour, 2007), Lectures (Dailey-O'Cain, 2000; Perez \& Macia, 2002), academic genres (Abdi, 2002; Blagojevic, 2003; Bunton, 1999; Longo, 1994; Mauranen, 1993; Ventola \& Mauranen, 1993), and student writings (Connor, 1984; Field \& Yip, 1992; Intraprawat \& Steffensen, 1995; Johns, 1984; Johnson, 1992;

Karasi, 1994; Norment, 1994; Steffensen \& Cheng, 1996). These studies have targeted their use patterns of frequency.

Judging from the work reviewed thus far, DMs play an important role in a text's cohesion and coherence. The writer of this paper can assume that discourse markers have some relationship with a discourse's cohesion, texture and coherence. Then the writer can put forward a hypothesis: in order to make their English writing more cohesive and more coherent, besides reference, substitution and ellipsis, students are also very likely to use discourse markers in their essays. If this is true, teacher should be clear about how their students use discourse markers and how they use discourse markers correctly and appropriately. Knowing that, teachers can take positive and effective steps when they teach English writing. Therefore, There is a significant relationship between teaching discourse markers and enhancement.

Considering the theoretical issues discussed above, the present study attempted to provide plausible answers to the following questions:

1. Is receiving instruction on how to use DMs helpful to improve writing ability?

2. Is DMs instruction related to self-perceived success of learners in writing in a foreign language?

3. Does instruction of DMs increase the level of learners' English proficiency?

Discussions and studies regarding DMs usually concern EFL writing (e.g., Fengi, 2010) and usually focus on some specific markers such as Well and $O h$ and their role in oral communication ( see Lee, 2000) with the exception of Traugott (1995) who related DMs to theory of grammaticalization. Further, recent years have seen an emergence of studies investigating DMs from a number of different perspectives e.g. Halliday and Hassan's (1976) seminal work on cohesion in English; however, they didn't speak directly of discourse markers. In the meantime, Fraser's (1990 \& 1998) theoretical framework concerns the meaning of sentence. Therefore, seeing the need to better understand this powerful construct, we designed a study to investigate the productive role of DMs in writing. In explaining discourse markers to learners, instructors can explain that such words are helpful or necessary whenever they are writing. 


\section{Method}

\subsection{Participants}

The participants of the present investigation consisted of 20 Iranian learners of English in Shoukoh Iran English Institute in Tabriz, Iran. Their age ranged from 14 to 23 years with the average of 16.5 years old and all participants studied at intermediate level. To be unbiased, they were chosen randomly, most of them were students at high school level and a few were university students. The cohort in this study was small, because it was a classroom based study.

\subsection{Materials and Procedure}

Two sets of discourse cloze tests, an extension of cloze procedure in which deletion of information carrying propositions are avoided, instead linguistic elements which establish interrelationships between the text propositions (cohesive devices and rhetorical markers) are deleted, were administered to these participants, the first one as pre-test to evaluate their homogeneity, and after treatment the second test as post-test was administered in order to collect

data for this study So the participants were asked to fill these gaps with suggested markers. The discourse cloze was 13-item, multiple-choice, rational-deletion discourse cloze tests.

\subsection{Procedure}

The first discourse cloze test was given to the participants of both groups and some introductory oral explanations were given. The participants were allowed to ask questions. They were asked to complete the gaps only with markers which they know as the best selection to fill in the blanks and create cohesion in the text. The evaluation of the obtained "mean" and their standard deviation revealed the fact that these two groups of the subjects were to a great extent homogenous. Then experimental group have received a treatment about discourse markers which were found in natural and authentic texts, and told them the different functions each play in creating a meaningful text. In fact, the focus of the treatments was on those families of conjunctives or those individual conjunctives which were used more frequently and extensively. The researcher has chosen the ones which are frequently used in the reading texts, such as: As well as, besides, moreover, and similarly (additive); although, however, on the other hand, though, and yet (adversative); because, for, since, thus, therefore, (causal); as soon as, finally, first, then, and until (temporal), actually, after all, as though, in case, in fact, and such as (other types), then the description of the roles that they play in the context. Note an example from this instruction:

I got school, but it was late.

She failed. However, she has tried her best.

At the end of the treatment sessions, we managed to have participants complete the second discourse cloze test in order to evaluate the effectiveness of the treatments in enhancing participants' understanding of discourse markers.

\subsection{Data Analysis}

In this study, the Exact Word Method was used to score the cloze tests. The data obtained from two groups' performance was analyzed statistical. The scores on the two tests were analyzed and a correlation analysis was performed on them. The correlation coefficient was 0.82 , which suggests a high homogeneities between two groups' ability to recognize DMs roles in creating both cohesion and coherence texts. The relationship between their scores on the two tests was calculated using the software SPSS, through t-test formula. The mean and SD of Table 2 presents mean values for cloze test completion by using suitable DMs for each group in pre-test, while Table 3 shows the findings of post-test of both groups, through t-test formula.

<Tables 1- 3 about here>

\section{Results}

The result of tests of both groups implied that the more knowledge about discourse markers, the more cohesion text they can produce. Definitely, experimental group's learners created cohesion text in more efficient way than learners who do not know the role of discourse markers. Table 1 presents mean values for cloze test completion by using suitable DMs for each group in pre-test that shows their homogeneities.

While Table 2 shows the findings of post-test of both groups, their difference performance after treatment sessions, the mean (15.01 and 18.75) and standard deviations (2.04 and 6.55) of two sets of scores indicate the high relationship between the instruction of DMs and subjects' ability in production of both cohesion and coherence texts.

Table 3 shows the main characteristics of the scores of 20 subjects who took the two discourse cloze tests. Through SPSS software, it be concluded a value of -6.8 with 5 d.f. is significant at the .001 level. Therefore, the writer of the 
paper has evidence to support the claim that the instruction of DMs would be helpful for improvement in writing ability. As a result, the research hypothesis that instruction of DMs can enhance the learners' writing ability was supported by the results of the statistical analyses.

\section{Discussion}

A good writing is not only grammatical, but also cohesive and coherent. Discourse markers have main role in cohesion of text, and should hold a central place in writing teaching. Nobody can't say discourse markers are decisive for English writing, but anybody can't deny they have great effect on the cohesion and coherence of writing. The production of coherent discourse is DMs signals a relationship between discourse units, i.e. utterances, longer spans of text, even between the text and the extra-linguistic context. The option of DMs refers to the fact that they are almost always syntactically optional, i.e. they can removed without altering the grammaticality of the host sentence (Degand, 2010). This does not mean that DMs have no function whatever in the utterances they occur in (ibid, 2010). A slight improvement has been detected in writing ability.

As shown in both Tables $(1 \& 2)$, analysis revealed statistically significant differences between groups in the use of DMs in their cloze tests. This finding shows that as learners are instructed about DMs, their level of creating more cohesion text also improve. This is to be expected as learners becoming more equipped may feel safer in dealing with composing a text.

The strong relationship between learning DMs roles within a text and perceived success in establishing a cohesion text was identified ( $n=10 \quad M=18.55$ and also .001 level of significance), as shown in Table 3, implying that the more knowledge learners have about DMs, the more successful they can be in the writing process. Text with more DMs were considered as more cohesive though DMs are by no means the only evidence for a well-organized and cohesive text. Note an example from pre-test:

After graduating from college, she worked as a secretary. But she didn't give up her dream. She spent her lunch hour writing stories, mainly for adults. Then in 1990, on a train trip to London, she got the idea for the boy wizard.

This is in keeping with previous research that reported a positive impact of instruction of DMs on success in language writing (Feng, 2010). Obviously, learners who can cope with writing task, dealing with creating cohesion text, feel more successful in writing in a foreign language. This finding on the other hand is supported with former research by Traugott (1995), who has accounted the effect of DMs' relationship with self-perceived success of learners in writing in a foreign language.

One of the aims of learner training is to help learners become independent in the learning process and become more confident with writing task of language learning. Therefore, learners who can become more educated can better composing of cohesion text. To see whether receiving

any form of such instructions influences writing proficiency, such a finding indicates that the more learners receive instruction about knowing of reading in a foreign language, the more

proficient they can become of writing skill. Without a doubt much more investigation is necessary to determine the precise role of learner training in improving writing skill.

An interactive process that requires speakers to draw upon several different types of communicative knowledge-cognitive, expressive, social, textual that complement more code-based grammatical knowledge of sound, form, and meaning (Schiffrin, 1992). Discourse markers mention not only about linguistic properties ( e.g. semantic and pragmatic meaning ), but also about the cognitive, expressive, social, and textual competence of those who use them ,because the functions of markers are so broad, and all analyses of markers can teach about their roles in discourse (ibid, 1987:67). Basing decisions about marker status on data analysis has an important consequences. On the basis of the findings of this paper it is concluded that instruction of discourse markers can be one of basic process in developing of writing ability, and learners profit from it and use it in an efficient way. Accordingly the research writers' prediction that learners' awareness of discourse markers' role in written would facilitate creating of a cohesion text is confirmed and this is reflected in the learners' written performance. The finding of this paper is supported by other papers which is related to this topic, such as "Discourse Markers in English Writing "by Li Feng who concludes that discourse markers function as one of the cohesive devices between words and sentences. He also believes that during English teaching, especially during English writing teaching, discourse markers should paid attention.

With most cases of overuse and misuse of DMs in learners' cloze test, the writer follows Demirci and Kleiner (1997) who suggest that DMs are used in their writing as a result of translation from their first language to target language. Some of the students in control group used DMs which overshadowed the text and made it difficult to understand; on the 
contrary, experimental group used DMs in meaningful way. Note an example from control groups' performance (S10) with more misuse of DMs:

After returning home, she was broke but living in a small, cramped apartment. She continued writing, however, in 1995, finished the first book.

Kubota (1998) specifically found that insufficient L2 skills account for the lack of attention to organization, the use of the simple text structures, ineffectiveness in connecting paragraphs, or inadequate paragraphing. Even though the students' classroom teachers may not directly teach discourse marker use, but students may be modeling that use in the classroom, and they satisfy themselves with the idea that if they use too many DMs, they are making their composition more cohesive and acceptable (Jalilifar, 2008). So the writers' hypothesis that instruction of DMs is necessary and needed is rejected with Jalilifar's finding that 'high' achievers use more DMs and are more likely to direct their attention to creating of cohesion and coherence text than to generating short grammatical sentences. On the other hand, the findings of this study is supported by Moradan's study (1995), investigated the effect of explicit teaching of DMs on the appropriate use of DMs by students in their writings and found that the students' conscious awareness of forms and implications of DMs improved their appropriate use of DMs. He also found that comparison of DMs in the first language and English had a great advantage for the students. Therefore, he suggested that explicit instruction of DMs should be involved in language course to help learners take advantage of their knowledge of DMs in reading comprehension and other language uses.

In the meantime, Innajih (2007) investigated the effect of explicit instruction of DMs on the reading comprehension of the second language learners. The participants in the treatment group were explicitly taught DMs types and their relation to reading comprehension. The result showed that the treatment group performed better than the control group on the discourse cloze test. And also, Stoodt (1972, as cited in Innajih, 2007), in a cloze study, found a significant relationship between reading comprehension and the comprehension of DMs.

Thornbury (1997) reiterated that "cohesion alone is not enough to make a text coherent" (P.126). Texts have an internal logic, which the reader recognizes even without the aid of explicit cohesive devices. Students need to know that there are a number of other linguistic devices that affect the extent to which groups of sentences hold together and form a complete and cohesive text such as reference words (e.g. pronoun reference, article reference, ellipsis etc.), lexical sets, lexical repetition, as well as conjunctions (Jalilifar, 2008).

In fact using of DMs is just one part of grammar. Traugott (1995) defines grammaticalness as a process where, by lexical material in highly constrained pragmatic and morpheme-syntactic contexts become grammatical and already grammatical material becomes more grammatical (P.37). In her study, she found out that development of DMs coincides with development of highly specific constructions via strategic use in discourse to a sequential adverbial and ultimately a DM. According to Fraser (1988) DMs are part of grammar by carrying on the label of pragmatic markers, and then they should be somewhere between grammar and discourse comes to vogue, then they could be part of grammar and discourse (PP.21-23). So grammar develops via pragmatic strengthening which ends up with the use of DMs; for this reason, the use of DMs demands experiential language learning (Jalilifar, 2008).

The absence of DMs does not necessarily show a sentence ungrammatical, it's just a removing of some powerful clues, which make relationship between the current utterance and the prior discourse. As Lichtenberk (1991) said "Grammar shapes discourse, and discourse, in return, shapes grammars" (p.78).

A study by Nunan (1999) indicated that the "background knowledge was a more important factor than grammatical complexity in the ability of the readers to comprehend the cohesive relations in the texts" (p. 260). Thus, comprehension of DMs and cohesive relations, on one hand, and overall creation of a text, are highly interrelated. What the results of the study suggest is that for a better writing text, learners need to comprehend and recognize meanings and functions of DMs, that is, they require to have a good command of DMs. Therefore, suggestion could be explicit instruction of DMs, their meaning and functions in different contexts.

\section{Pedagogical Implications}

The result of the research clearly revealed the importance of teaching text markers to students in increasing their awareness about the place of their usage in a written text. Writing not only employs the procedure of a good written text, but depicts and values the coherence and cohesion, too. Composing a lot of sentences without considering the cohesive ties fails to negotiate the inter-related events intended to be decoded by the reader. Then the presence of text markers is a necessary condition to have a smooth and enjoyable written text. Based upon the fact, the syllabus designer should believe that including these elements in texts books and materials is a necessity. In the meantime, the related topics are related to teachers. It means that teachers should believe that writing as one of the four language skills should be taught 
to students. Instructors ought to emphasize on these text markers which are used frequently and are prevalent in a written text of any nature. As the research by Innajih (2007) shows, explicit instruction of DMs is to the advantage of second language learners. In fact explicit teaching of DMs seems to influence all language skills since they are important components of language. As some studies have shown (Moradan 1995, Nunan 1991), it is recommended that the instructor compare the DMs in English with those in the students' first language. Students must be aware that the writing skill is one of the important and difficult tasks to learn. Learning to write well of course is a matter of art, inherited in some people by nature; it requires to be equipped with some knowledge as well one of the useful elements is to be familiar with text binding devices, among them text markers.

\section{References}

Brown, G. \& G. Yule. (1983). Discourse Analysis. Cambridge: Cambridge University Press.

Degand, L. (2009). On Describing Polysemous Discourse Markers. What does translation add to the picture? University Catholique de Louvain. [Online] Available: http://www.uclouvain.be/cps/ud/doc/vailbel/documents/Degand-polysemy-proofread.pdf.

.Halliday, M.A. (1970). A course in spoken English: Intonation. London: Oxford University Press.

Halliday, M.A. and R.Hasan. (1976). Cohesion in English. London: Longman.

Hatch, E. (1992) Discourse \& Language Education. Cambridge: Cambridge University Press.

Feng, L. (2010). Discourse Markers in English Writing. Journal of International Social Research, Vol. 3/11, Spring 2010. [Online] Available: http://www.sosyalarastimalar.com

Fraser, B. ( 2002). An approach to discourse markers. Journal of Pragmatics. Vol. 14, Issue 3. [Online] Available: http://dx.doi.org/10.1016/0378-2166 (90)90096-V

Innajih, A. (2007). The effect of conjunctive types on the English language reading comprehension of Libyan university students. [Online] Available: www.ecls.ac.uk/publish/text/the Effect of Conjunctive/

Jalilifar, A.R. (2008). Discourse Markers in Composition Writings: The Case Of Iranian Learners Of English as a Foreign Language. Journal of CCSE, English Language Teaching, Vol.1, No.2, December 2008. [Online] Available: http://ccsenet.org/journal/index.php/elt/article/view/460.

Jucker, A. ( 2002), The discourse marker well: A relevance-theoretical account. Journal Of Pragmatics, Vol. 19, Issues 5, May. [Online] Available: http://esweb.uzh.ch/ahjucker/Jucker_1993_well.pdf.

Kubota, R. (1998). An investigation of L1-L2 transfer in writing among Japanese university students: Implication for contrastive rhetoric. Journal of Second Language Writing, 7, 69-100. [Online] Available: http://www.ingentaconnect.com/content/els/10603743/1998. http://dx.doi.org/10.1016/S1060-3743(98)90006-6

Lee, K. (2000), Discourse Markers Well and Oh. University of Illinois at Urbana-Champaign, United States. [Online] Available: http://exchanges.state.gov/media/oelp/teaching-pragmatics.

Lichtenberk, F. (1991). On the gradualness of grammaticalization. In E.C. Traugott and B.Heine, (Eds.) Approaches for grammaticalization (pp.37-80). Amsterdam: Benjamins.

Moradan, A. (1995). Significance of conjunctions as a cohesive device in teaching writing. Unpublished MA thesis. Allameh Tabatabai University.

Schiffrin, D. (1987). Discourse Markerts. Cambridg: Cambridge University Press.

Traugott, E.C. (1995). Subjetification in grammaticalization. In D, Stein \& S, Wright, (Eds.), Subjectivity and subjectivization: Linguistics perspectives (pp.31-54). Cambridge University press.

Traugott, E.C. (1995). The role of the development of Discourse Markers in a Theory of Grammaticalization. Paper presented at ICHL XIL, Manchester, (1995), Version of 11/97. [Online] Available:

http://www.staford.edu/ traugott/ect-papersonline.html

Yule, G. (1985). The study of Language: An Introduction. Cambridge University Press. 
Table 1. Means and Standard Deviation of Pre-test

\begin{tabular}{|l|c|c|c|}
\hline Groups & Number & Mean & Std. Deviation \\
\hline Control Group & 10 & 14.9 & 1.49 \\
\hline Experimental Group & 10 & 14.8 & 1.71 \\
\hline
\end{tabular}

Table 2. The Result of Post-test

\begin{tabular}{|l|c|c|c|}
\hline Groups & Number & Mean & Std. Deviation \\
\hline Control Group & 10 & 15.01 & 2.04 \\
\hline Experimental Group & 10 & 18.75 & 6.55 \\
\hline
\end{tabular}

Table 3. Data on Cloze Post-test

\begin{tabular}{|c|c|c|c|c|}
\hline Subject Number & Control Group & Experimental. G & $\mathrm{D}$ & $\mathrm{D}^{2}$ \\
\hline 1 & 16.75 & 20 & 3.25 & 10.56 \\
\hline 2 & 16.5 & 20 & 3.5 & 12.25 \\
\hline 3 & 16 & 19.5 & 2.5 & 6.25 \\
\hline 4 & 15.75 & 19 & 3.5 & 12.25 \\
\hline 5 & 15.5 & 18.75 & 3 & 9 \\
\hline 6 & 15.25 & 18.25 & 3 & 9 \\
\hline 7 & 14 & 18 & 4 & 16 \\
\hline 8 & 14 & 18 & 4 & 16 \\
\hline 9 & 14 & 17.5 & 3.5 & 12.25 \\
\hline 10 & 13 & 17.5 & 4.5 & 20.25 \\
\hline
\end{tabular}

